\title{
A Detached Leaf Technique for Studying Race-specific Resistance to Cladosporium caryigenum in Pecan
}

\author{
Patrick J. Conner ${ }^{1}$ \\ Department of Horticulture, University of Georgia, Coastal Plain Experiment Station, 4604 Research Way, \\ Tifton, GA 31793
}

\begin{abstract}
AdDitional INDEX words. Carya illinoinensis, scab, vertical resistance, fungus, microscopic, histology, stain, trypan blue, chlorazole black E

Abstract. A detached leaf screening technique was developed for studying specific interactions between pecan [Carya illinoinensis (Wangenh.) C. Koch] cultivars and isolates of the pecan scab fungus, Cladosporium caryigenum. Monoconidial isolates were obtained from leaf scab lesions on 'Wichita', 'Desirable', 'Cape Fear', and 'Elliot'. Each isolate was then inoculated onto detached leaves of each of the four cultivars and fungal growth was observed under the microscope after eight days. 'Wichita', 'Desirable', and 'Cape Fear' isolates produced subcuticular hyphae at a much higher frequency when inoculated back onto the cultivar from which they were isolated in comparison to the other cultivars. The 'Elliot' isolate was able to produce a high frequency of subcuticular hyphae when inoculated onto 'Elliot' and 'Cape Fear', but not when inoculated onto 'Desirable' and 'Wichita'. Field inoculations conducted with the 'Wichita' and 'Desirable' isolates validated the detached leaf protocol. The results obtained indicate that pecan scab is composed of multiple races with a high degree of specificity for host cultivars. A rapid whole-leaf staining system is presented which appears to have wide applicability to assessing fungal growth in leaves.
\end{abstract}

Pecans [Carya illinoinensis (Wangenh.) C. Koch] are attacked by a wide range of pathogen and insect pests which cause substantial crop losses. In the humid growing conditions of the southeastern United States, the most economically damaging pest is the fungus Cladosporium caryigenum which causes pecan scab. Scabinfection reduces both yield and quality of nuts, and if uncontrolled results in total crop loss (Sanderlin, 1994). Commercial pecan plantings often require 8 to 11 applications of fungicides in a growing season in order to remain profitable (Ellis et al., 2000). Pecan scab has developed resistance to at least one common fungicide, Benlate (Sanderlin, 1992), and recent concerns over negative environmental health effects of pesticides has increased pressure to restrict valuable control agents (Guillebeau, 1998). Many important high quality cultivars, including 'Stuart' and 'Desirable' which comprise over one half of Georgia's pecan acreage, are becoming increasingly susceptible to the scab pathogen. Development of scab resistant cultivars with excellent commercial quality would increase the profitability of pecan culture in the southeastern U.S.

High levels of scab resistance are available in pecan germplasm (Thompson and Grauke, 1994). However, few cultivars contain sufficient resistance so that fungicide applications are not necessary, and most resistant cultivars lack many of the nut quality traits required commercially. A major emphasis of cultivar development for the Southeast is the incorporation of high levels of scab resistance into high quality commercial cultivars (Conner, 1999; Goff et al., 1998; Thompson and Grauke, 1994). One of the most important factors to be considered in the development of a resistance screening protocol is the presence of multiple races of the scab pathogen (Hunter et al. 1986). The existence of scab races is inferred by the observation that many cultivars vary in susceptibility in different locations and over time (Sparks, 1992; Demaree and Cole, 1929), and has been demonstrated empirically by resistance tests with specific isolates (Demaree and Cole, 1929; Converse, 1960; Bracewell, 1996). This variability complicates field testing of

Received for publication 5 Nov. 2001. Accepted for publication 9 May 2002. The author thanks William Goff for help in obtaining the pathogen isolates used in this work.

${ }^{1}$ Corresponding author; e-mail: pconner@tifton.cpes.peachnet.edu. germplasm because all relevant races are not likely to be present at any one testing location.

Typical techniques of screening for resistant germplasm involve field ratings for the presence of scab lesions on the leaves or nuts (Goff et al., 1998; Thompson and Grauke, 1994). A disadvantage of this method is dependence on favorable environmental conditions for pathogen development before ratings can be taken. Replication of these tests is hindered by annual rainfall variations and difficulty in grafting plant materials. Variation in race makeup of the local scab pathogen populations also will likely influence these tests, producing differences in observed cultivar susceptibility between locations.

To bypass these inherit difficulties in conducting field tests for resistance, Yates et al. (1996) developed a detached leaf method for assessing cultivar resistance to pecan scab. This method has the advantage of a standardized test environment in which the inoculation is being conducted, facilitating reproducibility between tests. Additionally, rare isolates of the pathogen can be tested without their release into the environment. However, this procedure made use of a cumbersome staining procedure and was not tested with multiple isolates of the pathogen. This protocol was modified by adopting a faster staining system and tested with multiple isolates of the pathogen to evaluate its potential for screening germplasm and breeding progenies for race-specific resistance to pecan scab.

\section{Materials and Methods}

ISOLATE PREPARATION. Isolates were obtained from each of the four cultivars; 'Wichita' (Wi-Tif-2), 'Desirable' (De-Tif-3), 'Cape Fear' (Cf-Au-2), and 'Elliot' (El-Au-2), and named using a host cultivar-geographic location-isolate number system. 'Wichita' and 'Desirable' leaves were collected from the experimental orchards of the Coastal Plain Experiment Station located in Tifton, Ga. 'Cape Fear' and 'Elliot' leaves were collected from experimental orchards near Auburn, Ala. Conidia from individual lesions were suspended in a drop of water and spread across a petri dish containing $1 \%$ water agar. Plates were incubated at room temperature for $24 \mathrm{~h}$ and then single germinated conidia were transferred to potato dextrose agar containing the antibiotics streptomycin, chloramphenicol, and tetracycline at $50 \mathrm{~g} \cdot \mathrm{L}^{-1}$. Plates were placed in a growth chamber set at 
$24{ }^{\circ} \mathrm{C}$ with a $12 \mathrm{~h}$ photoperiod provided by fluorescent lights $(115$ $\mathrm{mmol} \cdot \mathrm{m}^{-2} \cdot \mathrm{s}^{-1}$ ) for a period of 2 weeks. Fungal colonies were then homogenized in sterile water and placed on sporulating media consisting of oatmeal agar amended with the above antibiotics, and returned to the growth chamber. After incubating the plates for 7 to $14 \mathrm{~d}$, conidia were harvested by adding $2 \mathrm{~mL}$ of sterile water to the plate and rubbing the surface with a rubber policeman. A frozen stock of the isolate was prepared by freezing germinated conidia on filter paper discs according to the method of Baxter and Fagan (1986) except that the discs were stored at -80 rather than $-8^{\circ} \mathrm{C}$.

INOCULUM PREPARATION. Isolates to be used in the experiment were revived from frozen stocks by placing filter paper discs with the dried germinated conidia directly onto oatmeal agar plates. After 2 weeks of growth the fungal colonies were homogenized in sterile water and spread across a fresh oatmeal agar plate which was again incubated for 2 weeks. Subsections of this plate were homogenized in water and spread onto oatmeal agar plates to produce conidia for inoculations. After 1 to 2 weeks growth, conidia were harvested and the concentration adjusted to $1 \times 10^{6}$ conidia per $\mathrm{mL}$ of water with a hemacytometer.

DETACHED LEAF ASSAY. Leaves for the assay were collected from field-grown trees which had not received fungicide sprays. Young leaves, from $1 / 3$ to $2 / 3$ fully expanded were disinfected for 2 min in a $10 \%$ solution of commercial bleach and then rinsed twice in distilled water. Leaves were blotted dry and placed in deep well petri plates $(100 \times 20 \mathrm{~mm})$ on top of moist vermiculite. Leaves were sprayed with the conidial suspension using a chromatography sprayer until runoff. Control leaves were sprayed with sterile water. Plates were sealed inside of an airtight plastic container and kept at $100 \% \mathrm{RH}$ for $48 \mathrm{~h}$ at $24{ }^{\circ} \mathrm{C}$ under a $12 \mathrm{~h}$ photoperiod $\left(115 \mathrm{mmol} \cdot \mathrm{m}^{-2} \cdot \mathrm{s}^{-1}\right)$. Plates were then removed from the box and uncovered until the surface of the leaf had dried. Plates were then recovered and kept in the growth chamber with water being added periodically to the vermiculite to keep it moist.

For microscopic examination of disease progress, whole leaf mounts were observed. A $1-\mathrm{cm}^{2}$ section was cut out of the center of the leaf for each sample. Samples were placed in a histoprep plastic capsule (Fisher Scientific, Atlanta, Ga.) and cleared in a solution of $50 \%$ $\mathrm{EtOH}, 50 \%$ glacial acetic acid at $70{ }^{\circ} \mathrm{C}$ for 20 min. Leaf sections were then placed in a solution of $5 \% \mathrm{KOH}$ and autoclaved for $1 \mathrm{~h}$ at $121^{\circ} \mathrm{C}$. Capsules were then placed in a solution of $1 / 3$ water, 1/3 lactic acid, 1/3 glycerol containing $0.01 \%$ trypan blue and $0.01 \%$ chlorazole black $\mathrm{E}$, and autoclaved for $1 \mathrm{~h}$ at $121^{\circ} \mathrm{C}$. The samples were allowed to cool until lukewarm and the excess stain was washed away with $50 \%$ glycerol. Stained leaves were then mounted in 50\% glycerol and examined immediately or stored for several days withno loss of staining. Ten leaves of each cultivar/isolate/time period were inoculated. On each leaf section 50 germinated conidia were examined for the presence of subcuticularhyphae, reproductive initials, and conidiation, for a total of 500 germinated conidia observed for each test. Differences in fungal growth between cultivars were deter-

mined statistically through the use of a Kruskal-Wallis one-way analysis of variance on ranks (Sigmastat).

Field inOCulation. Field inoculations were made by spraying expanding young leaves with a conidial suspension until runoff. Leaves were then wrapped loosely with a moist paper towel and enclosed in a plastic bag. The plastic bag was then covered with aluminum foil to reflect the heat. Control inoculations were treated in the same manner except that they were sprayed with sterile water. Leaves were covered for $48 \mathrm{~h}$ and then uncovered to dry. Leaves were collected 21 or $28 \mathrm{~d}$ after inoculation and examined under a dissecting microscope for the presence of scab lesions. Infection frequency was determined as the number of lesions on the leaf divided by the area of the leaf. Differences in infection frequency were determined statistically through the use of a Kruskal-Wallis one-way analysis of variance on ranks.

\section{Results}

DetaChed LEAF INOCULATIONS. Initial studies to determine the optimum number of days postinoculation (PI) to observe the infec-

Fig. 1. Chronology of pathogen development on resistant and susceptible cultivars. Leaves of the four cultivars were inoculated with Cladosporium caryigenum isolated from the 'Wichita'. Leaves were examined microscopically at 4 (A), 8 (B), and 14 (C) d postinoculation. The percent of the germinated conidia producing subcuticular hyphae, reproductive initials, and sporulation were determined. Mean totals with a common letter are not different $(P<0.05)$ by ANOVA on ranks test.

\section{A}

Isolate Wi-Tif-2, 4 days P.I.

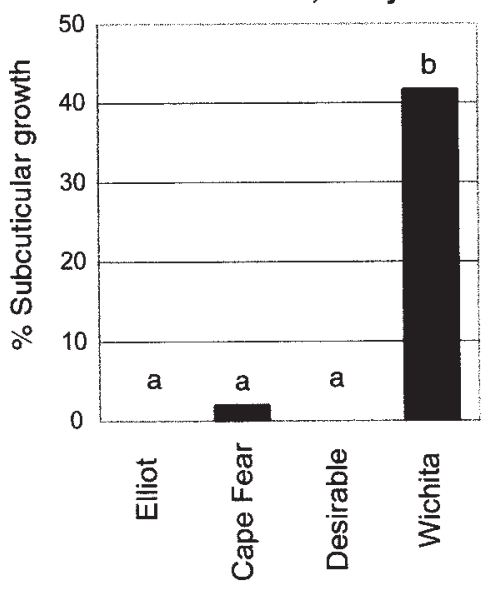

Isolate Wi-Tif-2, 14 days P.I.

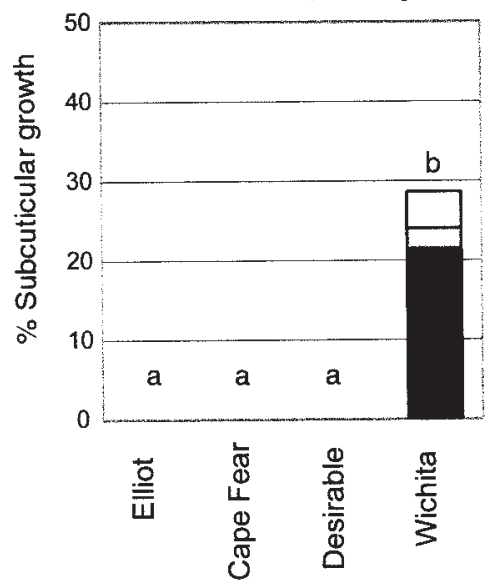

Isolate Wi-Tif-2, 8 days P.I.

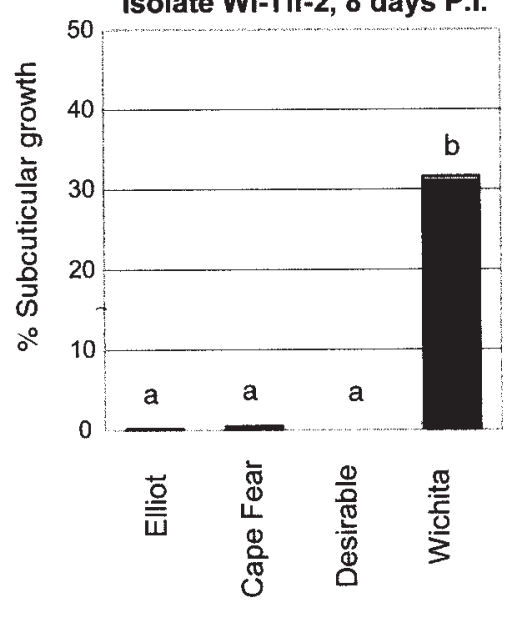


tion process were undertaken by challenging each of the four cultivars with the 'Wichita' scab isolate, Wi-Tif-2. At $4 \mathrm{~d}$ PI conidia had germinated and formed germ tubes and appressoria on leaves of all four cultivars. Inoculating Wi-Tif-2 conidia on to 'Wichita' leaves showed over $40 \%$ (Fig. 1A) of the conidia penetrating the cuticle underneath the appressorium and producing clearly visible subcuticular hyphae between the cuticle and epidermal cell layer (Fig. 2A). Hyphal growth was concentrated just above the anticlinal cell wall junctures. By contrast, no subcuticular hyphae were evident in 'Elliot' and 'Desirable' samples and there were only $2 \%$ in 'Cape Fear' (Fig. 1A). Epidermal cells underneath the germinated conidia on these samples appeared normal or expressed darkened halos in the area around the appressoria (Fig. 2B).

By $8 \mathrm{~d}$ PI, subcuticular hyphal growth was observed underneath $31 \%$ of the germinated conidia on the 'Wichita' leaf samples (Fig. 1B). Subcuticular growth continued to expand radially outward from the initial infection point below the appressorium (Fig. 2C). In some samples hyphae were seen growing below the epidermal layer and into the palisade parenchyma layer. Reproductive initials were observed at $0.6 \%$ of the germinated conidia sites. These were evidenced by the formation of a pair of brown colored cells on a lateral protrusion of the subcuticular hyphae (Fig. 2D). The first cell is smaller and lighter brown than the more distal cell. Condiophores are produced as extensions of the dark brown distal cells and erupt up through the cuticle. Only a small percentage $(<1 \%)$ of germinated conidia had formed subcuticular hyphae in the 'Elliot' and 'Cape Fear' samples, and no subcuticular growth was observed in the 'Desirable' samples (Fig. 1B).

In the final observation period at $14 \mathrm{~d} \mathrm{PI}$, subcuticular growth could be observed at $29 \%$ of the germinated conidia on the 'Wichita' leaf samples (Fig. 1C). By this time the hyphae had grown extensively radially outward from the initial infection point. Hyphae had also penetrated into the interior cell layers and could be observed within the palisade and parenchymalayers. Reproductive initials were associated with $3 \%$ of the germinated conidia and an additional $5 \%$ had produced a conidiophore which had burst through the cuticle and extended above the leaf surface (Fig. 2D). Thus at $14 \mathrm{~d}$ PI nearly a third of all growing lesions had entered the reproductive phase. No evidence of continued pathogen growth was observed on the 'Elliot', 'Cape Fear', or 'Desirable' leaf samples. Occasionally subcuticular hyphal fragments surrounded by a dark halo were observed, suggesting that hyphal growth had taken place but had been arrested at some time prior to this sampling.

To investigate race-specific resistance among the pecan cultivars, the four pathogen isolates were inoculated onto 'Desirable', 'Cape Fear', and 'Elliot' leaves and observed after eight days of growth. Eight days PI was chosen as the optimum time for assessing fungal growth because at this point the hyphae had grown large enough to be easily visible and the leaves were still fresh and healthy. As with Wi-Tif-2, subcuticular hyphae were associated with significantly more germinated conidia when the De-Tif-3 and Cf-Au-2 isolates were inoculated back onto the same cultivar from which they were isolated (Fig. 3A and $\mathrm{B}$ ). Isolate El-Au-2 differed from the other isolates in that it produced a large percentage of subcuticular hyphae when inoculated onto a cultivar other than that from which it was isolated (Fig. $3 \mathrm{C})$.

Field inOCULATIONS. Field inoculations were conducted with the two isolates obtained locally in order to compare to the results from the detached leaf inoculations. Field inoculations validated the results from the detached leaf study in that the greatest infection frequency resulted from inoculation of a cultivar with an isolate obtained from that cultivar (Table 1). Isolate Wi-Tif-2 produced a large number of lesions on 'Wichita' leaves but not on the other three cultivars. Similarly De-Tif-3 produced a large number of lesions on 'Desirable' leaves but only a small number of lesions on the other three cultivars. Increasing the sampling period from $21 \mathrm{~d}$ to $28 \mathrm{~d}$ did not increase the number of infections observed using the De-Tif-3

Fig. 2 Development of Cladosporium caryigenum isolate Wi-Tif-2 in susceptible and resistant pecan leaf tissue. Germinated conidium with germ tube and subcuticular hyphae after $4 \mathrm{~d}$ growth on 'Wichita' leaf (A). Germinated conidia on a resistant 'Desirable' leaf after $4 \mathrm{~d}$ growth $(\mathbf{B})$. Germinated conidium with expanded subcuticular hyphae after $8 \mathrm{~d}$ growth on 'Wichita' leaf $(\mathbf{C})$. Sporulating lesion on 'Wichita' leaf after $14 \mathrm{~d}$ growth $(\mathbf{D})$. Abbreviations: $\mathrm{c}=$ condium, gt = germ tube, $\mathrm{sch}=$ subcuticular hyphae, $\mathrm{pb}=$ pale brown cell, $\mathrm{db}=$ dark brown cell, $\mathrm{cp}=$ conidiophore, $\mathrm{r}=$ running hyphae, $\mathrm{a}=$ appressorium, $\mathrm{h}=$ halo .
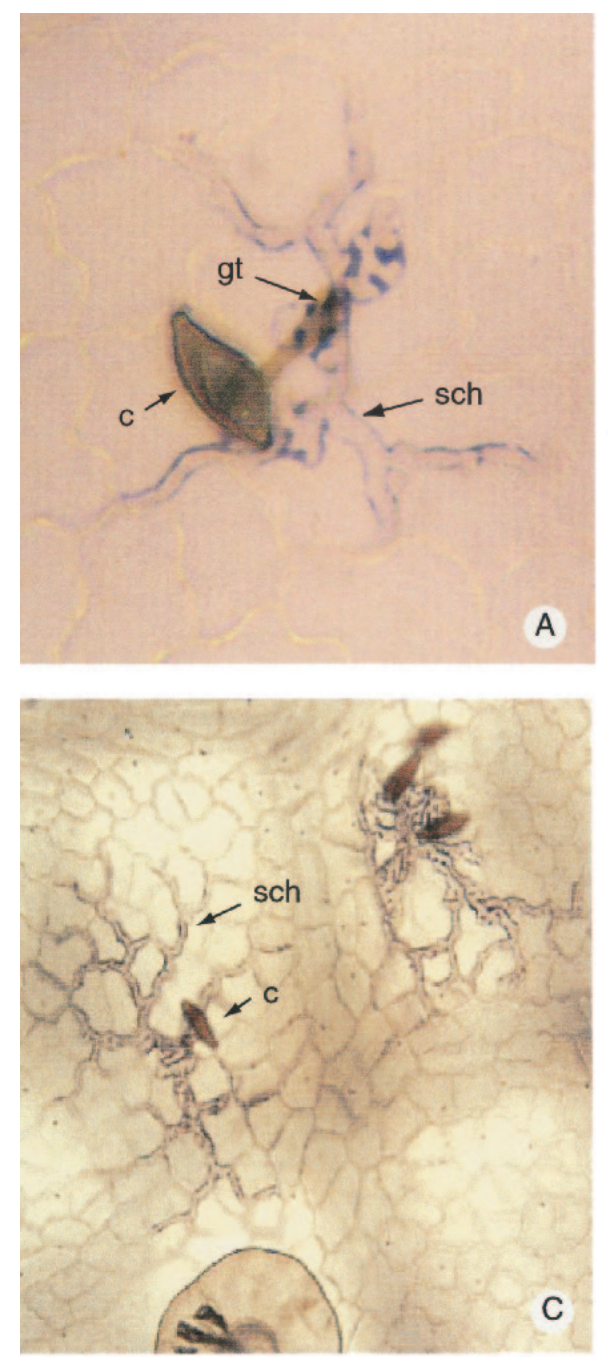
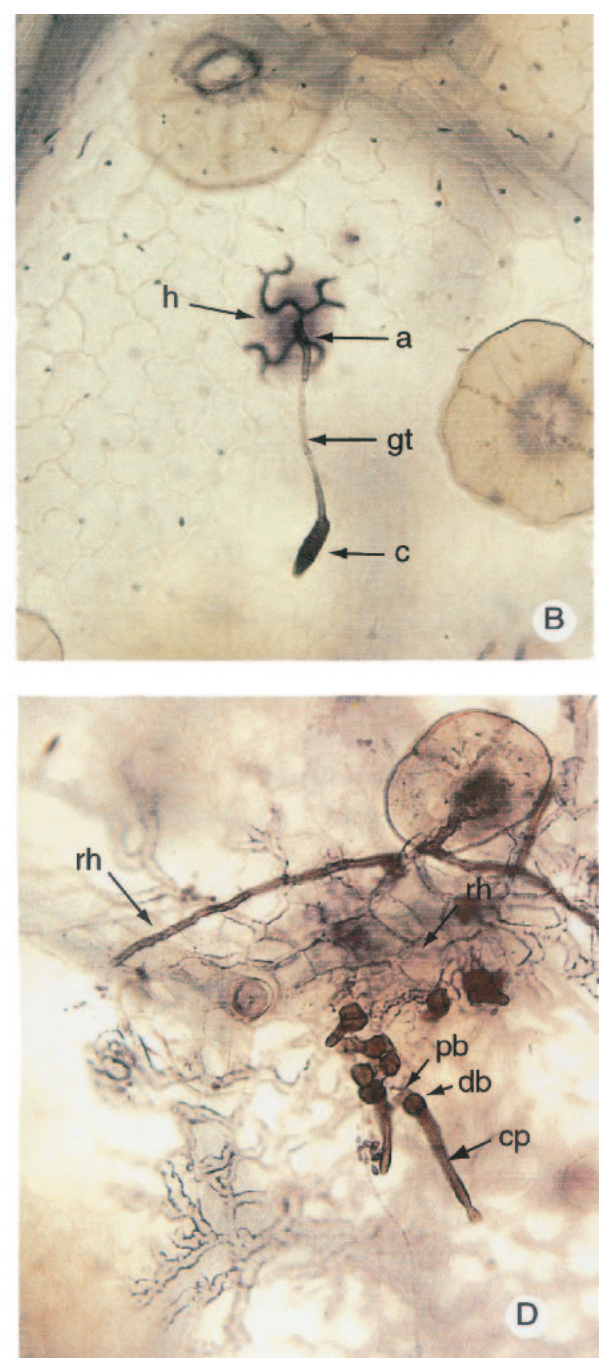
isolate (Table 1), indicating that $21 \mathrm{~d}$ is an adequate time period for lesions to develop.

\section{Discussion}

A detached leaf screening system is highly advantageous in this plant-pathogen system because the size of the host plant makes greenhouse and growth chamber studies difficult. While field inoculations can be performed, the release of foreign pathogen isolates of unknown virulence is undesirable. The combination of detached leaf inoculations with microscopic examination of pathogen development worked well in assessing race-specific resistance of the cultivars. The staining system used here represents a distinct advantage over previous systems in terms of ease of use and clarity in visualizing fungal hyphae. Previous studies made use of a chloral hydrate-acid fuchsin staining system that requires several days to complete (Latham and Rushing, 1988; Yates et al., 1996). In contrast, the $\mathrm{KOH}$-chlorazole black E/trypan blue system can be completed in just a few hours, allowing results of resistance tests to

Fig. 3. Genotype influence on the ability of Cladosporium caryigenum to produce subcuticular hyphae on the host leaf. Leaves of the four cultivars were inoculated with monoconidial isolates obtained from 'Desirable' (A), 'Cape Fear' (B), and 'Elliot' (C). Leaves were examined microscopically 8 days postinoculation and the percent germinated conidia producing subcuticular hyphae were determined. Mean totals with a common letter are not different $(P<0.05)$ by ANOVA on ranks test.

A

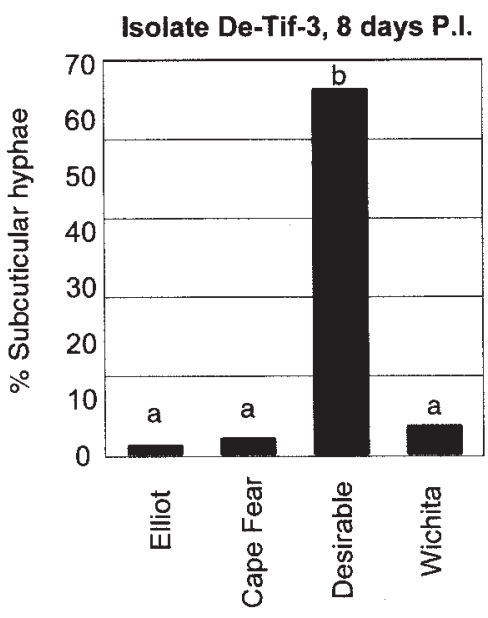

Isolate El-Au-2, 8 days P.I.

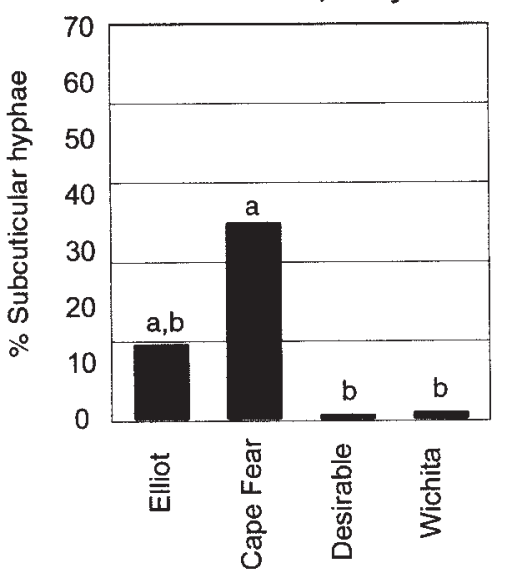

be obtained in just over a week from the initial inoculation. The use of $\mathrm{KOH}$ to remove the cytoplasm from the host cells also greatly increases the clarity of the samples. All cellular layers of the leaf can often be observed, and the depth of penetration of the fungal hyphae assessed. Slides have been observed after 1 year of storage with no noticeable loss of staining.

Yates et al. (1996) demonstrated that detached leaves could be used to differentiate a resistant from a susceptible host using a single strain of the pathogen. Conidia germination, germ tube development, and appressoria formation developed with equal frequency on resistant and susceptible hosts as well as nonhosts. However, subcuticular hyphae were observed in much greater frequency on susceptible 'Wichita' leaves as compared to the resistant 'Elliot' leaves. It thus appears that the critical step in host resistance occurs sometime after appressoria formation and before the formation of extensive subcuticular hyphae. This work with the Wi-Tif-2 isolate mirrors that of Yates et al. (1996). The Wi-Tif-2 isolate was able to germinate and develop germ tubes and appressoria on all cultivars. However, subcuticular hyphae were observed much more frequently in 'Wichita' leaves, the cultivar from which it was isolated, than in the other three cultivars. The three resistant cultivars consist not only of a highly field resistant genotype 'Elliot', but also a field susceptible genotype 'Desirable', and a moderately field resistant genotype 'Cape Fear'. These three genotypes did not differ in their reaction to Wi-Tif-2, showing that field susceptible cultivars possess resistance to some scab isolates. After two weeks of growth sporulating lesions developed on 'Wichita' B leaves, demonstrating that detached leaves are a suitable host for the pathogen. Comparisons between field inoculations and detached leaf studies further demonstrated the utility of this method for resistance screening.

Clearly, the four scab isolates varied in virulence, providing further evidence of a high degree of host specificity. Converse (1960) tested several isolates in greenhouse inoculations and found that for all isolates self-inoculations resulted in the highest number of sporulating lesions and several isolates were only pathogenic to their original hosts. Cross-inoculations which were successful usually produced abnormal lesions and lower levels of sporulation. In field tests, Demaree and Cole (1929) demonstrated that heavy scab infections only occurred when inoculation was made on a variety from which the conidia were taken. The only exception to this rule in the current study was the result obtained with isolate El-Au-2, which produced subcuticular hyphae in 'Cape Fear' in a frequency as great as that in 'Elliot', its original host. This isolate differed from the other three isolates in that it was collected from a leaf with only a single lesion, while the other isolates were obtained from leaves with multiple large lesions. Since this isolate had not seemed to produce an epidemic infection on 'Elliot', a cultivar which seldom scabs badly, it may represent an isolate which is only partially adapted to the cultivar from which it was obtained.

In summary, this research indicates that 
Table 1. Number of scab lesions per square centimeter produced from field inoculations of four pecan cultivars with two pecan scab isolates.

\begin{tabular}{lcccc}
\hline \hline & \multicolumn{2}{c}{ Time } & \multicolumn{3}{c}{ Cultivar inoculated } \\
\cline { 2 - 5 } Isolate & period $^{\mathrm{z}}(\mathrm{d})$ & Wichita & Desirable & Cape Fear \\
\hline Wi-Tif-2 & 21 & $1.95^{\mathrm{y}} \mathrm{a}$ & $0.00 \mathrm{~b}$ & $0.00 \mathrm{~b}$ \\
De-Tif-3 & 21 & $0.03 \mathrm{a}$ & $1.59 \mathrm{~b}$ & $0.00 \mathrm{a}$ \\
De-Tif-3 & 28 & $0.00 \mathrm{a}$ & $1.13 \mathrm{~b}$ & $0.00 \mathrm{~b}$ \\
& & & $0.00 \mathrm{a}$ \\
\hline
\end{tabular}

${ }^{\mathrm{z} N u m b e r}$ of days between inoculation and sample counts. Any two means within a row not followed by the same letter are significantly different at $P \leq 0.01$.

${ }^{\mathrm{y}}$ Number of scab lesions per $\mathrm{cm}^{2}$.

Inoculation test not performed.

pecan cultivars display vertical or race-specific resistance to pecan scab. Results to date indicate that the scab pathogen consists of a large number of races, each well-adapted to its host cultivar. Therefore, a resistance breeding program should challenge potential new cultivars with a wide range of scab isolates in order to lower the likelihood of escapes being misclassified as resistant. Screening programs are much more likely to be successful if they test cultivars over multiple locations, or use defined inoculum sources from diverse locations and cultivars. Additionally, studies aimed at identifying pathogen diversity over locations and across host genotypes will be useful in identifying the best method of providing pathogen diversity.

\section{Literature Cited}

Baxter, L.W. and S.G. Fagan. 1986. Method for maintaining three selected fungi. Plant Dis. 70:499-500.

Bracewell, C. 1996. Pathogenic variation of Cladosporium caryigenum on resistant and susceptible pecan cultivars. MS thesis, Univ. Ga., Athens.

Conner, P.J. 1999. The Georgia pecan breeding program. Proc. S.E. Pecan Growers Assn. 92:77-80.

Converse, R.H. 1960. Physiologic specialization of Fusicladium effusum and its evaluation in vitro. Phytopathology 56:527-531.

Demaree, J.B. and J.R. Cole. 1929. Behavior of Cladosporium effusum (Wint.) Demaree on some varieties of pecan. J. Agr. Res. 18:363-370.

Ellis, H.C., P. Bertrand, and T.F. Crocker. 2000. 2000 Georgia pecan pest management guide. Univ. Ga. Coop. Ext. Serv. Bul. 841.

Goff, W.D., M. Nesbitt, R. Mullenax, F. Raspberry, and B. Graves. 1998. Pest resistant cultivars as a way to reduce input costs, p. 79-90. In: B. McCraw, E.H. Dean, and B.W. Wood (eds.). Pecan industry: Current situation and future challenges. Proc. 3rd Natl. Pecan Wkshp., USDAARS.

Guillebeau, P. 1998. What to do about the food quality protection act? Or how can we protect the pesticides we need? Proc. S.E. Pecan Growers Assn. 91:65-69.

Hunter, D., T. Thompson, and R. Sanderlin. 1986. Control of pecan diseases through genetic resistance. Proc. S.E. Pecan Growers Assn. 79:51-54.

Latham, A.J. and A.E. Rushing. 1988. Development of Cladosporium caryigenum in pecan leaves. Phytopathology 78:1104-1108.

Sanderlin, R.S. 1992. Survey of Louisiana pecan orchards for scab pathogen populations tolerant to benomyl fungicide. Proc. S.E. Pecan Growers Assn. 85:123-127.

Sanderlin, R.S. 1994. Effect of nut scab on pecan yield and quality components, p. 45-58. In: M.W. Smith, W. Reid, and B.W. Wood (eds.). Sustaining pecan productivity into the $21{ }^{\text {st }}$ Century. Proc. 2 nd Natl. Pecan Wkshp., USDA-ARS.

Sparks, D. 1992. Pecan cultivars: The orchards foundation. Pecan Production Innovations, Watkinsville, Ga.

Thompson, T.E. and L.J. Grauke. 1994. Genetic resistance to scab disease in pecan. HortScience 29:1078-1084.

Yates, I.E., D. Maxey, S. Lee, D. Sparks, and C.C. Reilly. 1996. Developing the pecan scab fungus on susceptible and resistant host and nonhost leaves. J. Amer. Soc. Hort. Sci. 121:350-357. 